\title{
Risk Assessment of the Coping and Adaptation Mechanisms for Pastoralists to Climate Change and Variability: A Case Study of Kongelai Ward, West Pokot County, Kenya
}

\author{
Raphael P. Magal ${ }^{1}$ and Boniface N.Wambua ${ }^{2, *}$ \\ ${ }^{1}$ Postgraduate Programme in environmental planning and management, Department of Geography \& Environmental Studies, \\ University of Nairobi \\ P.O. Box 30197-00100 GPO, Nairobi, Kenya \\ ${ }^{2}$ Department of Geography \& Environmental Studies, University of Nairobi, \\ P.O. Box 30197-00100 GPO, Nairobi, Kenya \\ "Corresponding author's email: wambua_boniface [AT] uonbi.ac.ke
}

\begin{abstract}
The study was undertaken in Kongelai Ward, West Pokot County, because of its vulnerability to changing and erratic rainfall pattern which has adversely affected pastoralism. The research focused on better understanding of climate change and variability on two climatic factors, rainfall and temperature, in order to provide insights on pastoralists' risk management adaptations at a micro-level. In addition, it investigated the use of Indigenous Knowledge. Pearson chi square test was performed to test the hypothesis on whether there is an association between climate variability and change, and coping and adaptation strategies utilized by the Pokot community. Both primary and secondary data was used. Household questionnaire survey, focus group discussion and key informants interviews were used to collect primary data at household and community levels. Primary data (through questionnaires) was collected from a sample survey of 98 households taken from 5,596 households. multi-stage sampling technique was used, and information obtained was analyzed using inferential and descriptive statistics. Results indicated that, 94\% of the farmers use Indigenous knowledge. Coping strategies include: Selling livestock (90\%), relief food supply (90\%), cash/food-for-work (71\%), Slaughter of old and weak livestock (58\%), consumption of wild fruits (33\%), consumption of bush products, (50\%), off-farm employment (30\%), and minimization of food for consumption (84\%). Diversification of livelihood (92\%), Livestock mobility (94\%), sending children to school (56\%), Strategic livestock feed (35\%), Develop water sources (15\%), Change in diet consumption (78\%), Livestock off-take (25\%),Storage of pasture (35\%), were identified as some of the most commonly used adaptation strategies. Recommendations include; better planning and target interventions, Awareness creation on environment, alternative income source, support pastoralists adaptation and coping strategies, enhancement of extension services, documentation and dissemination of indigenous knowledge, and enhance pastoralists' resilience to drought and heat stresses.
\end{abstract}

Keywords--- climate change and variability; indigenous knowledge, coping and adaptation mechanisms

\section{INTRODUCTION}

\subsection{Background to the study}

As a result of multiple stresses and low adaptive capacity, studies have shown that Africa is highly vulnerable to climate change and vulnerability with projected mean warming ranging from $0.2^{0} \mathrm{C}$ to more than $0.5^{\circ} \mathrm{C}$ per decade (Sivakumar et al, 2005; Boko et al, 2007). Sivakumar et al, (2005) Christensen et al, (2007) reported that the warming in Africa is anticipated to be much higher in the drier sub-tropical regions than the rest of the world. 
In relation to rainfall, Sivakumar et al, (2005) pointed out substantial change in rainfall in both arid and semi-arid tropics of Africa over the last 60 years resulting in noticeable changes in both frequency and intensity of extreme events eg flooding. Likelihood of increase in annual mean rainfall in East Africa has been indicated in the climate change and variability projections. Recurrent droughts have resulted in water stress and greatest risk to agriculture. For effective mitigation and adaptation, the challenges of climate change and variability needs to be addressed holistically including how indigenous knowledge (IK) can complement climate change monitoring, mitigation and adaptation measures.

According to IPCC (2001), Hulme et al, (2002) and Titus et al, (2009), the impacts of climate change and variability have been documented in different research studies carried out across the entire world with anticipated impacts manifesting itself in the form of; floods, storms, prolonged droughts and increased atmospheric temperature (IPCC 2007).Impacts of the phenomenon will be experienced in economic, social and environment according to UNDP (2007).

Both natural and anthropogenic factors contribute to climate change and variability. Among the natural causes include Continental drift, mountain building, deviations in the earth's orbit, and variations in solar radiation while anthropogenic factors for instance the increase in carbon dioxide levels as a result of emissions from fossil fuel combustion and aerosols are contributed by human activities that impact on climate. In addition, other concern on the roles they play in affecting climate, micro-climate and measures of climatic variables include change in land-use, depletion of ozone layer, agriculture and deforestation according to (Fisher et al, 2002; IPCC 2007).

An estimated total of 268 million pastoralists reside in Africa who inhabit 43 percent of land mass and account between 10 to 44 percent of the Gross Domestic Product of their respective countries according to African Union's policy framework for pastoralism (2010).Pastoralism has enormous potential and is manifested in poverty reduction, economic growth generation, environmental management, sustainable development enhancement, and building climate resilience which is being recognized as a vital role by 2010 African Union's policy framework. Pastoralists are experiencing rapid changes in their environment and welfare as a result of increase in a series of subsequent droughts resulting to high mortality of livestock numbers as pasture and water sources disappear. In addition to increased human population and settlement impacting traditional grazing grounds and resulting competition for dwindling water sources, pastoralists often suffer from occasional floods. All these challenges faced by pastoralists are happening under inadequately developed infrastructure characterized by poor market linkages and weak and unprepared institutions.

Uniqueness of pastoral areas from the rest of the country is attributed to mobility of livestock and people, their demography which is characterised by low population density and high population growth and their institutions which embraces customary mechanisms for the management of natural resources and security and in addition possesses invaluable indigenous knowledge. These unique characteristics are rarely included in the national policy or practice.

Focus on the future of pastoralism is the subject of national and global discussions on climate change and variability forcing the scientific community to generate knowledge and share experiences and best practices offering possibilities for pastoralism and its livelihoods.

According to ASAL Policy 2012, addressing of structural inequalities which is the backbone of household socioeconomic vulnerabilities in the ASALs environments is paramount as compared to interventions and polices that only aim to increase access to water resources, early warning systems, crop irrigation, markets and drought mitigation measures, on their own which are not adequate for enhancing adaptive capacity of the vulnerable communities. Pastoralism is a free-range livestock production system whereas in some communities it is a source of livelihoods which is practiced in all of Africa's dryland regions, but will pastoralism continue to exist in the changing climatic episodes?

\subsection{Justification of the study}

Due to increased drought events as in the year 2008 and 2009, and thereafter in 2010 and 2011 calls for need of integrated examination of coping mechanism and human less model combined as adaptation strategies for long term resilience to drought. According to Smith et al, (2001) Polifosova et al, (2001); Paavola et al, (2008); Headey et al, (2013), and Ecker et al, (2013) violent conflicts have provided compelling justification for effective adaptation mechanisms in the Horn of Africa whereby studies have shown increased vulnerability in the wake of climate change. Therefore this study is justified because of the following reasons; 
- Climate change and variability affects crops and livestock production and the impacts are felt more on pastoralists since they occupy the fragile arid and semi-arid lands where occurrence of drought is rampant.

- West Pokot County being ecologically sensitive environment with poor soil quality, poor infrastructure, and weak governance and normally responds drastically to changes in the climate are being depended upon which render the pastoral communities even more susceptible to climate changes (Bante et al,2008., and Abagalla et al,2008).

- According to (Akegbejo et al, 2009) currently constrained research and extension can be enhanced with low cost solutions with indigenous knowledge.

- IK can be used to highlight other form of knowledge since it is a different form of knowledge and it can used to highlight unnoticed aspects in of climate monitoring, which have gone unnoticed, or given inadequate attention in 'western' science.

- Recognition of pastoralists local innovativeness offers an entry point for bottom-up approach for enhancing adaptation and coping mechanisms than only climate change and variability.

- The study was undertaken in Kongelai Ward because of its vulnerability to unpredicted rainfall pattern which has adversely affected pastoralism due to variations in climatic conditions affecting coping and adaptation strategies. The model helps to visualize that a large part of Kongelai Ward receives erratic and unreliable rainfall with most of the areas having high rate of evaporation.

- Thus the model in the case study is important in showing the possibility of Pokot communitys' future in relation to adaptation strategy to climate change and variability

\subsection{Scope and limits of the study}

Interactions of different factors including ecological, socio-economic and socio-political factors have led to vulnerability of Pokot pastoral livelihoods to impacts of climate change and variability which constrains their livelihoods and ecosystem structure. This case study is important by analyzing different factors that leads to their vulnerability and their responses in attempt to reduce vulnerability. The study shows new emerging coping and adaptation models and changes in vulnerability. Among the variables addressed in the study include; climate change, indigenous knowledge, adaptation and coping strategies of the Pokot pastoralists. Furthermore, it will also consider some of the implications of the findings, including the cultural consequence.

The research covers West Pokot County which is characterized by a variety of topographic features. West Pokot County is one of the 14 Counties in the Rift Valley region. It is situated in the North Rift along Kenya's Western boundary with Uganda. It borders Turkana County to the North and North-East, Trans-Nzoia County to the South, Elgeyo Marakwet County and Baringo County to the South East and East respectively and also on Western side it shares an international boundary with Uganda. The County lies within Longitudes $34^{\circ} 47^{\prime}$ and $35^{\circ} 49^{\prime}$ East and Latitude $1^{0}$ and $2^{0}$ North. It covers a surface area of 9,169.4 square kilometers and has a population of 512,690 with a population density of 59.33 per square kilometre (KNBS, 2009).It has three main livelihood zones namely PastoralAll species, Agro Pastoral and Mixed farming.

The County experiences a bimodal type of rainfall with the Long Rains falling between March and June while the Short Rains fall between September and November. Rainfall varies from $400 \mathrm{~mm}$ (lowlands) to 1,500 $\mathrm{mm}$ (highlands) per annum. Temperature ranges from a minimum of $10{ }^{\circ} \mathrm{C}$ to a maximum of $30{ }^{\circ} \mathrm{C}$ in different parts of the county. The county depends more on the Long Rains than the Short Rains for crop, regeneration of pasture and browse and recharge of water sources.

Agriculture and livestock constitutes the major activities of the County, since there is no major industrial or mining activity. The agricultural Pokot tribe is known as "Pi-pa pagh" the people of the flour and inhabits the escarpment and the foothills. The pastoral Pokot is known as the "Pi-po-tich" the people of the cattle and infringe upon the grazing of the Turkana and Karamojong. Kongelai Ward falls within the county lowlands where fluctuations in climate are experienced with structural challenges mainly due to poor infrastructure development that affects access to basic public services and general accessibility.

\section{MATERIAL AND METHODS}

\subsection{Sample size and sampling procedure}

Out of the 5,596 Households as a target population (KNBS,2009 Census) a sample of 98 households was randomly used in the selected villages in the study area after general observations which was made through the transect survey (East-West, North- South) prior to the start of the field survey. Using Nasuirma Model formula to arrive at the sample size, a total of 98 households were selected to form the study population. 
A multi-stage random sampling procedure was adopted in order to select participating villages and households for interviews. Kongelai Ward was purposively sampled based on geographical location, dominant livelihood activity and vulnerability to drought events. Afterward the Locations within the Kongelai Ward was listed and categorized on the basis of the various livelihood zones- land-use systems activities, accessibility and the extent to which they will be perceived to be prone to extreme climatic events. This was then followed by random selection of three study Sub- locations from Serewo, Kitalakapel and Poole. After random selection of the study Sub-locations, the total number of households was obtained from the Kenya National Bureau of Statistics records for the area. The questionnaires were distributed to the three Sub-Locations based on the total population (Kitalakapel 43, Serewo 28, and Poole 27). After getting the households from the respective Sub-locations, the respondents (head of households) were selected randomly to participate in the research. Therefore, every head of household had a chance of being selected to participate in the research.

Sample distribution in each Sub-Location

\begin{tabular}{|l|l|l|}
\hline SUB-LOCATION & NO. OF HOUSEHOLDS & SAMPLED HOUSEHOLDS \\
\hline Kitalakapel & 309 & 43 \\
\hline Serewo & 204 & 28 \\
\hline Poole & 197 & 27 \\
\hline TOTAL 6,606 & SAMPLE TOTAL $=\mathbf{9 8}$ \\
\hline
\end{tabular}

source: researcher 2016

\subsection{Methods of data collection:}

A formal household survey was conducted using a standard questionnaire. Questionnaires was administered to the household heads and was designed to capture information on family characteristics (educational, marital status, family size, age, gender) as well as other parameters such as indigenous knowledge, local perception about climate change and variability, their coping and adaptation strategies, unreliable rainfall onset and seasonal distribution. The questionnaires constituted both structured and unstructured questions. The purpose for the structured questions was to get information that facilitated data analysis and classification in a specific way. On the other hand un-structured question was to seek an in-depth response.

Key informants included Village elders and personnel from government, Community Based Organizations (CBOs) and non-governmental organizations (NGOs). They also included extension workers, local administrators, decisionmakers and leaders of relevant NGOs. Key informant interviews was appropriate for generating information and ideas in situations when general descriptive information was needed, and when understanding of the underlying motivations and attitudes of a target population was required. The interview focused on climate pattern, Pastoralists, impact of climate variability and change, indigenous knowledge and coping and adaptation strategies.

Focus group discussion with community leaders, elders and experienced pastoralists was carried out using guide checklist questions so as to explore local knowledge practices in climate adaptation and coping strategies. A total of 3 FGDs were carried out in Kongelai, Kitalakapel and Serewo Sub-Locations. FGDs were used to complement the information obtained from the key informant interviews. FGDs participants were selected based on their role in the community, acceptance with community and knowledge of the culture and social organization of the community. FGD approach offered the opportunity of allowing people to probe each other's reason for holding a certain view and it was used to validate and triangulate the responses that came out of household survey

Field observations was made on the impacts of climate variability and change on livelihoods sources. Observation was carried out in respondent's homes, grazing fields and surrounding environments and photographs was also taken. Observation technique was utilized to triangulate the information gathered from other sources.

Secondary data was collected from books, journals, maps, reports and other research publications. Development related secondary information (e.g. reports and policy documents) was reviewed/synthesized to get idea of pastoralism and development policies, their implementation and impact in the county.

\subsection{Data Analysis}

The collected data (quantitative) were analyzed using Statistical Package for Social Sciences (SPSS). Data collected through personal interviews were subjected to descriptive analysis. The information on changing aspects of climate, impacts of climate change on Pokot pastoralists, Indigenous knowledge strategies used and the type of communication used as sources of information were summarized in terms of frequency tables, charts and graphs to 
facilitate description and explanation of the study. Inferential statistics, notably Pearson Chi-square analysis was used in testing the hypothesis.

\section{RESULTS AND DISCUSSIONS}

\subsection{Socio-economic characteristics of the respondents}

\subsubsection{Gender of the respondent}

The results showed that 40 of the respondents were female whereas male respondents accounted for 58.This implies that the society is male dominated who determine important decisions as pertains the access and utilization of natural resources within the society. In the FGDs, gender of the household head, livestock ownership and herd size, access to extension services were found to influence households' perception of climate change. According to the Socio-economic factors that were assessed, changes in climate such as increase in temperature and decrease in the length of rainy seasons are more likely to be perceived by female-headed households than their male counterparts. The findings show that gender of household head significantly influenced the likelihood that a household took up the climate variability and change adaptation strategies. In the study area, female-headed households were more likely to take up climate variability and change adaptation because they are responsible for most of the household welfare activities and have better experience on various farm based production practices. In contrast, studies in the Nile basin of Ethiopia indicate that male-headed households adapt more readily to climate change (Hassan and Nhemachena 2008).

\subsubsection{Age of the respondent}

Majority of the respondents were within the ages between 31 and 50 years and accounts for $45.9 \%$ which is a reproductive age group; $18-30 \mathrm{yrs}$ accounts for $30.6 \%$; while above $51 \mathrm{yrs}$ accounts for $21.4 \%$; while those who don't know accounts for $2 \%$.

In the study area, households live in clustered homesteads with an average family size of six persons. This is higher than the national household average of 5.1 persons (Kenya National Bureau of Statistics 2013). The average size of household had a significant and positive influence on the likelihood that pastoralist cope and adapt to climate change. Larger households are associated with higher labour endowments, which would enable the household to accomplish various production tasks (Nhemachena and Hassan 2007; Silvestri et al. 2012). Household age was important demographic factor determining how vulnerable a household could be. For example, households headed by person above 50 years of age are more likely to be vulnerable compared with the younger persons. Consequently, elderly household heads are probably worse off in terms of preparing strategies to cushion their families against adverse climatic stresses and impacts and likely to make them more vulnerable.

\subsubsection{Level of education of the household head}

The study area is dominated by male headed household heads, 74 respondents with no formal education and low literacy level. This implies that most farmers have felt the changing climatic conditions but don't understand or rather know the causes of such changes which could have been attributed to high illiteracy levels and poor sources of information leading to low awareness levels. The level of education of the household head is important since it enables them to utilize ICTs/model which creates awareness through early warning system that prepare them in the event of weather variability.Illiteracy has hindered the community's ability to predict rainfall patterns and plan grazing managements accordingly.

\subsubsection{Household's main source of income}

The finding shows that pastoralism is the main source of livelihood in the study area, and that most respondents derive their income from livestock production (69\%) although livestock keeping alone for most households in the study area is not enough to secure their livelihood. Other farm activities households engage in were crop production, mixed farming and poultry production. Most livestock species kept by households were goats, sheep, camels, cattle and donkey. The results suggest a shift in herd composition in an attempt to adapt to changing climatic conditions since goats and camels were increasing in numbers and are known to be more resilient to drought compared to cattle (Toulmin 1996; Kagunyu and Wanjohi 2014). However, some of the respondents (31\%) also engaged in off-farm activities. Frequent weather variability means that Pokot pastoralists do not have enough food for better part of the year. In order to cope with these situations, households are engaging in wage labour, receiving cash remittances 
from relatives and government, engaging in sale of charcoal and firewood, and are also venturing in other small businesses enterprises.

This study suggest that access to affordable credit facilities is likely to eases cash constraints and allows households to invest in production inputs for climate variability and change adaptation. Similarly, cash transfers and remittance from relatives and friends are important determinants of climate change and variability adaptation and normally allow households to have additional cash for livelihood diversification (Bryan et al. 2009). Farm income has a positive and significant impact on the probability that pastoralist adapt to climate change and variability. Given the climatic-induced challenges facing households in the drylands, income from livestock has previously been reported to play an important role for enhancing climate change adaptation (Rao et al. 2011). Other farm based income activities include small scale sorghum production and Aloe cultivation.

\subsection{Households' perceptions of climate change and variability}

Climate change and variability has been heard and experienced by $100 \%$ of farmers. In the research findings, it was clear that some farmers reported deforestation and pollution from the industries as the main causes of climate change and variability. Out of the farmers that were interviewed majority of them had experience on climate change and variability, 24 respondents had no idea at all on contributors of climate change. This calls for the need of awareness for farmers on climate change mitigation, adaptation and coping strategies. This implies that most farmers have felt the changing climatic conditions but don't understand or rather know the causes of such changes which could have been attributed to high illiteracy levels and poor sources of information leading to low awareness levels.

Majority (100\%) of the respondents perceived various changes in climatic factors in the study area. The perception of these changes, however, varies between different respondents. A high proportion of both respondents experienced changes in temperature and rainfall amount, frequency and length of rainy season over the last three decades. Most of the respondents $(100 \%)$ perceived increasing temperature, while none observed a decrease in temperature. This implies that households could be highly valuable key informants on studies related to climate change. The valuable knowledge of the pastoralist could also be used for climatic forecasting. Temperature increases are known to have a significant impact on water availability and pasture resources, thus likely to exacerbate vulnerability of the pastoralists (Hererro et al. 2010). With regard to rainfall amount, frequency and length of rainy season, households specified various changes they had perceived in the study area. Overall, 98 respondents perceived rainfall amounts to be decreasing, with 80 respondents indicating that rainfall had become highly variable and more erratic. These observations were consistent across the entire study area. 98 respondents also noted decreasing rainfall frequency and length of the rainfall seasons over the past 30 years. From the FGDs and interviews with key informants, majority confirmed a decrease in the number of rain days coupled with frequent droughts in 1990 to 1995,1999 to 2000, 2008 to 2009 and 2010 to 2011 . The main concern expressed by the respondents was about greater variability and seasonal changes, which hindered their ability to predict rainfall patterns and plan their grazing managements accordingly. In addition, many respondents reported that the shorter rainy seasons has led to longer dry periods in between seasons, which results in higher pressure on the available pasture resources. These observations by respondents correspond with reports from weather stations that revealed high level of variability of rainfall distribution over the past three decades in the arid and semi-arid environments of Kenya (Galvin et al. 2001; Shisanya et al. 2011).

In the analysis, households' perception of climate variability and change were found to be influenced by gender of the household head, livestock ownership and herd size, and access to extension services. From the socio-economic factors examined, the results suggest that female-headed households are more likely to perceive a change in climate such as increase in temperature and decrease in the length of rainy seasons than male-headed households. The fact that female-headed households are more likely to perceive changes may be because they are responsible for most of the household duties.

\subsection{Influence of climate change and climate variability on pastoral/agricultural activities at local / farm level}

The farmers interviewed reported that, reduced crop yield (100\%), crop failure (98\%), reduced soil moisture (68\%) change in planting time (65\%), increase in crop pest and diseases(40\%), were the highest climate change impacts in agro pastoralists' as compared to the pastoral areas. High crop/pasture failure was reported to be very high in pastoral area than in the Agro pastoral which may be attributed by low mean rainfall compared to agro pastoral area which receives higher mean rainfall. Low rainfall received in the pastoralists area have made them experience high pasture and crop failure as compared to the agro pastoralists highland areas where crop farming thrives very well. The most remarkable drought that had highest impact on farmers based on the results from the various discussions 
held with Key informants was in the year 2004 and 2009 which led to loss of livelihoods especially pastoralists who entirely depended on livestock. In the agro-pastoral area, crop failure and lack of adequate water for both animal and human consumption was also highly felt.

\subsection{Extent to which climate change and variability experienced has influenced on pastoral /agricultural activities at national level}

At the off-farm level insufficient food (98\%), high food prices (96\%), human wildlife conflict (28\%) and competition over resources, (45\%) and other impacts accounted for (7\%) were highly felt in agro pastoral areas compared to pastoral areas. This could have been attributed by high population rate in agro pastoral areas, reduced crop yield and nearness to reserved areas leading to high human wildlife conflict.

For the biophysical variables, the greater the level of household reliance on natural resources, such as pastoralism or dry land crop farming, the greater will be their vulnerability to climate change and variability. This is partly because the use of such natural resources is dependent on rainfall, which is projected to change. This study observed that almost all the postulated biophysical/ environmental variables contribute positively to household vulnerability. It is likely that the level of dependence on natural resources especially pastures and water will vary from household to household.

The determinants of households' vulnerability were found to be significantly influenced by the sex of the household head, age of the household head, size of the household, number of dependents, marital status, social linkages, access to extension services and early warning information. In addition, non-farm income, herd size and diversity, herd structure and herd mobility, access to markets, households' employment status, coping strategies and access to credit were also observed to be the key determinants of the households' vulnerability to climate-induced stresses. This concurs with studies by Eriksen et al. (2005) and Notenbaert et al. (2013) which similarly observed some of these factors to be the key determinant of households' vulnerability to climate variability and change in rural communities. The results are also consistent with previous findings by Kakota et al. (2011) and Gebrehiwot and van der Veen (2013). From these findings, there is still more to be done to understand the risk assessment of the coping and adaptation of pastoralists in the wake of climate change and variability

\subsection{Documentation of the indigenous knowledge used by the pokot community to cope with climate change and variability}

This study was carried out to find the level of indigenous knowledge usage by pastoralists and agro pastoralists' farmers and why they prefer to use indigenous knowledge in the management of their livestock and farms to address impacts of climate change and variability.

To evaluate farmers' perception regarding climate change and variability effects, farmers were asked if they have heard or experienced climate change in their localities, perceived causes of climate change and the most felt impacts of climate change on agriculture and livestock.

The results indicated that $100 \%$ of the respondents have heard and experienced effects of climate change and variability on their localities. Deforestation was thought by the farmers to be the highest contributor of climate change and variability, followed by pollution and global warming as the main causes of climate change having been reported by 98, 38, and 17 respondents respectively. Sand harvesting, soil erosion and overstocking were thought as least contributors of climate change having 6 respondents each while 24 of the households didn't know at all the causes of climate change and variability.

\subsection{Use of indigenous knowledge to cope with Climate Variability and Change}

The results indicated that, $94 \%$ of farmers still apply Indigenous knowledge in the management of their farms and livestock while $6 \%$ don't use it all. The reason behind using traditional approach is $83 \%$ accurate and $17 \%$ less accurate. $94 \%$ of the farmers still use Indigenous knowledge on agriculture/livestock keeping, prediction of different weather patterns and food preservation techniques in the management of their farms. The main reason behind relying on Indigenous knowledge (IK) more than scientific knowledge (SK) is that they are reliable, accurate and more affordable. The indigenous signs and strategies used by farmers for coping with climate change and variability were similar between the pastoralists and agro pastoralists because the study area is being predominantly occupied by the Pokot community. Migration of livestock and people was a very common strategy which is being practiced by the pastoralists more than the agro pastoralists which could be attributed by the fact that agro pastoralists are practicing preservation of pastures for the use during drought seasons unlike the pastoralists who reported to practice no pasture preservation at all hence the need to move in search of pastures in times of drought.

Some of the Positive indigenous strategies that are being practiced in the study area included; use of organic manure to increase crop production, crop rotation, traditional food preservation methods like smoking of meat, use of ash to 
preserve the seedlings, separation of livestock to control breeding, use of traditional herbs to treat some of the animal diseases and migration of livestock during drought.

Indigenous strategies practiced by the agro pastoralists more than the pastoralists were agro forestry, irrigation, planting of appropriate crop varieties, preservation of pastures, application of organic and inorganic fertilizers and soil and water conservation. On the other hand, pastoralists practice more of migration, planting of drought tolerant crops, rain water harvesting, keeping of drought resistant animals and management of pest and diseases. Livestock is an integral form of Pokot pastoralist community capital, besides functioning as a means of production, storage, transport and transfer of food and wealth (Behnke and Muthami et al, 2011).It is also essential for payment of dowry, compensation of injured parties during raids, symbol of prosperity and prestige, currency for exchange, store of wealth and security against drought, disease and other calamities.

During the FGDs, it came out clearly that the agro pastoralists are no longer practicing migration as compared to ten years ago while the pastoralists are now practicing it more due to frequent prolonged droughts and lack of pasture preservation. From the FGD also, it was clear that women from agro pastoralists' areas practice indigenous strategies such as traditional methods of food preservation examples dried white ants mixed with honey, consuming wild cassava "akan" and taking milk cream from gourd and use of organic manure in their farms, crop rotation and pasture enclosures. This explains the different activities practiced in both areas. The agro pastoralists produce their own agricultural food hence conversant with food preservation methods and with the few cattle they keep, they use the organic manure to enrich their soils for optimum food production. It was also clear that men from both areas are using traditional herbs to treat certain livestock diseases more than the women. This explains that men are the ones responsible for their cattle and they are the ones who also know specific traditional herbs to be used for treating specific diseases. The FGD results also indicated that women from pastoral areas prefer other strategies in coping with drought such as use of shallow wells to draw water, separation of livestock to control breeding as compared to the men who prefer migration of animals during drought in search of water and pastures. This could have been attributed by the facts that, during migration of livestock and people, women and children are left behind while men and boys move with the cattle.

The nomadic transhumance practiced by Pokot pastoralists is characterized by risk-spreading and flexible mechanisms, such as mobility, communal land ownership, large and diverse herd sizes, and herd separation and splitting (Schilling et al. 2012). The livestock types kept to manage and spread risk include cattle, camels, goats, sheep and donkeys. These livestock species have different forage and water requirements with variable levels of resilience during drought periods according to the FGDs. Livestock possession plays multiple social, economic and religious roles in pastoral livelihoods, such as providing a regular source of food in the form of milk, meat and blood for household members, cash income to pay for cereals, education, health care and other services. Crop farming has been acclaimed as a viable climate risk management and livelihood strategy for the sedentary farmers and agropastoralist (Smith et al,1998) others on the other hand view it as an unsustainable (even destructive) option for the rangelands especially with the challenges of climate variability and change. That notwithstanding, the Pokot pastoralists cultivate staple crops predominantly for own consumption but also sell what they produce in major urban centres of the County. 


\section{Testing of hypothesis}

\section{Chi-Square Tests}

\begin{tabular}{|c|c|c|c|c|c|}
\hline & Value & df & Asymp. Sig. (2-sided) & Exact Sig. (2-sided) & Exact Sig. (1-sided) \\
\hline Pearson Chi-Square & $5.660^{\mathrm{a}}$ & 1 & .017 & \multirow{6}{*}{.028} & \multirow{6}{*}{.019} \\
\hline Continuity Correction & 3.831 & 1 & .050 & & \\
\hline Likelihood Ratio & 7.958 & 1 & .005 & & \\
\hline Fisher's Exact Test & & & & & \\
\hline Linear-by-Linear Association & & & & & \\
\hline $\mathbf{N}$ of Valid Cases & 100 & & & & \\
\hline
\end{tabular}

a. 2 cells $(50.0 \%)$ have expected count less than 5 . The minimum expected count is 2.82 .

To test the hypothesis, Pearson chi square test was conducted to test whether there is an association between climate variability and change, and coping and adaptation strategies utilized by the Pokot community. In the analysis, Climate change and variability was independent variable while indigenous knowledge, coping and adaptation strategies were dependent variables.

The results gave a $\mathrm{p}$ value of $0.017, \mathrm{df}=1$. The $\mathrm{p}$ value is less than the 0.05 which was the desired significance level. This meant that the research hypothesis of Pokot pastoralists has not developed strategies of coping with Climate change and variability was rejected as there was sufficient evidence to do so. It was therefore concluded that there is a significant association between climate change and variability and coping and adaptation strategies. The null hypothesis is therefore, rejected for the alternative. The alternative hypothesis states that Pokot pastoralists have developed strategies of coping with climate change and variability. Hence there is an association between climate change and variability and the coping and adaptation strategies among the Pokot pastoralists. This means that there is a significant impact caused by the climate change and variability on the coping and adaptation strategies employed by the Pokot community. Despite the changing climate the community still continues to use their traditional coping and adaptation strategies to live and survive.

\section{CONCLUSIONS}

In Pokot community, majority of the pastoralists and agro-pastoralists are already taking measures to protect their lives and livelihoods against increasing drought events. However, majority find considerable challenges in their adaptation and coping strategies, only a few in the study area are able to withstand the impacts of frequent droughts. The community has rich indigenous knowledge which is highly held in tacit form. Ignorance of this indigenous knowledge has led to loss of traditional strategies, values and practices. Ways of integrating the rich indigenous knowledge with formal knowledge should be the new way to go for adaptation of climate variability and change. A way of communicating, disseminating, storing and retrieving by the use of Information and communication technologies should be devised for the indigenous knowledge to be useful for future generation.

Long term adaptations strategies to drought have been constrained by a number of socio-economic, political changes and deteriorating ecological conditions as per the FGDs.For instance, violent conflicts, lack of affordable credit facilities and financial services, limited access to markets, changing land tenure and poor infrastructure. Also problematic in addition, there are some indicators which include access to veterinary services, degradation of grazing lands and extension services. The main factors associated with increasing rangeland degradation in the area include over-exploitation of resources due to localized increase in human and livestock populations, changing land use patterns, Sedentarisation of the pastoralist, privatization of the communal land tenure, insufficient and unreliable rainfall and poverty caused by changing climatic conditions.

The study suggest that heads with higher level of education are likely to have better level of planning, access and understanding of early warning information for effective climate change adaptation. Thus strengthening education sector could be one of the key areas for building climate change resilience of the households in the study area. 
Important roles in strengthening the adaptation and coping strategies lies with the government, the private sector, non-governmental organizations, and donor agencies. It is critical in particular to value pastoralism as a productive and sustainable adaptation strategy for Pokots, by guaranteeing free and safe livestock mobility, improving the provision of security, access to education, markets and communication infrastructure. This ought to be coupled with offering affordable credit facilities, strengthening extension services, diversification of livelihoods, and enhancing livestock diversity and species for drought resilience.

The recently adopted Kenya ASALs policy is a good starting point but its implementation will be paramount in offering pastoralists' support required for effective adaptation and coping responses. Resilience to drought will remain a mirage without significant support by the government to reduce drought risks in Pokot, including violent conflict, households' resilience to drought.

This research therefore in a nut shell concludes that pastoralism remains one of the most important sustainable livelihood production systems in Pokot community with the right policies and targeted investment in identified adaptation and coping responses in the area.

\section{REFERENCES}

1. Akesbejo-Samsons, Y., 2009. Promoting local and indigenous knowledge in enhancing adaptive capacities under extreme events in Nigeria. In IOP Conference Series: Earth and Environmental Science (Vol. 6, No. 41, p. 412014). IOP Publishing.

2. Alila, P.O. and Atieno, R., 2006, March. Agricultural policy in Kenya: Issues and processes. In A paper for the future agricultures consortium workshop, institute of development studies (pp. 20-22).

3. Becker, C.M., 2001. World Bank. 2000. Entering the 21st Century:: World Development Report 1999/2000. New York: Oxford University Press for the World Bank. 11I am grateful to Richard Arnott and Andrew Morrison for valuable comments on an earlier draft of this review. Factual errors and misinterpretations, however, remain my own. Regional Science and Urban Economics, 31(6), pp.757-764.

4. Berkes, F. and Jolly, D., 2002. Adapting to climate change: social-ecological resilience in a Canadian western Arctic community. Conservation ecology, 5(2), p.18.

5. Gachathi, F.N. and Eriksen, S., 2011. Gums and resins: The potential for supporting sustainable adaptation in Kenya's drylands. Climate and Development, 3(1), pp.59-70.

6. Galvin, K.A., Thornton, P.K., Boone, R.B. and Sunderland, J., 2004. Climate variability and impacts on East African livestock herders: the Maasai of Ngorongoro Conservation Area, Tanzania. African Journal of Range and Forage Science, 21(3), pp.183-189.

7. Khisa, G.V., S.B.Oteng'i, S.M. Mikalitsa.2014.Effect of Climate Change on Small Scale Agricultural Production and Food Security in Kitui District, Kenya. The Journal of Agriculture and Natural Resources Sciences.1(1):34-44

8. Krätli, S., Huelsebusch, C., Brooks, S. and Kaufmann, B., 2013. Pastoralism: A critical asset for food security under global climate change. Animal Frontiers, 3(1), pp.42-50.

9. Luseno, W.K., McPeak, J.G., Barrett, C.B., Little, P.D. and Gebru, G., 2003. Assessing the value of climate forecast information for pastoralists: Evidence from Southern Ethiopia and Northern Kenya. World Development, 31(9), pp.1477-1494.

10. Mugenda, O.M., 1999. Research methods: Quantitative and qualitative approaches. African Centre for Technology Studies.

11. Mwaûra, C. and Schmeidl, S. eds., 2002. Early warning and conflict management in the Horn of Africa. The Red Sea Press.

12. Mwenda, A. and Kibutu, T.N., 2012. Implications of the New Constitution on Environmental Management in Kenya. Law Env't \& Dev. J., 8, p.76.

13. Nakashima, D. and Roué, M., 2002. Indigenous knowledge, peoples and sustainable practice. Encyclopedia of global environmental change, 5, pp.314-324. 
14. Oba, G., 2001. The effect of multiple droughts on cattle in Obbu, Northern Kenya. Journal of Arid Environments, 49(2), pp.375-3

15. Ogalleh, S.A., Vogl, C.R., Eitzinger, J. and Hauser, M., 2012. Local perceptions and responses to climate change and variability: the case of Laikipia district, Kenya. Sustainability, 4(12), pp.3302-3325.

16. Olukoye, G.A., Wakhungu, J.W., Wamicha, W.N., Kinyamario, J.J. and Mwanje, I., 2007. Livestock versus Wildlife Ranching in Kenyan Rangelands: A Case Study of Laikipia District Ranches. Kenya Veterinarian, 27(1), pp.24-30.

17. Olukoye, G.A., Wakhungu, J.W., Wamicha, W.N., Kinyamario, J.J. and Mwanje, I., 2007. Livestock versus Wildlife Ranching in Kenyan Rangelands: A Case Study of Laikipia District Ranches. Kenya Veterinarian, 27(1), pp.24-30.

18. Oluoko-Odingo, A.A., 2009. Determinants of poverty: lessons from Kenya. GeoJournal, 74(4), pp.311331.Printers.

19. Oluoko-Odingo, A.A., 2011. Vulnerability and adaptation to food insecurity and poverty in Kenya. Annals of the Association of American Geographers, 101(1), pp.1-20.

20. Omolo, N.A., 2010. Gender and climate change-induced conflict in pastoral communities: Case study of Turkana in northwestern Kenya. African Journal on Conflict Resolution, 10(2).

21. Opiyo, F.E., Wasonga, O.V. and Nyangito, M.M., 2014. Measuring household vulnerability to climateinduced stresses in pastoral rangelands of Kenya: Implications for resilience programming. Pastoralism, 4(1), pp.1-15.

22. Orindi, V.A., Nyong, A. and Herrero, M., 2007. Pastoral livelihood adaptation to drought and institutional interventions in Kenya. Human Development Report Office, Occasional Paper, 54

23. Parry, M.L., Canziani, O.F., Palutikof, J.P., Van der Linden, P.J. and Hanson, C.E., 2007. Contribution of working group II to the fourth assessment report of the intergovernmental panel on climate change, 2007. Climate Change 2007: Working Group II: Impacts, Adaptation and Vulnerability.

24. Pohl, C., Rist, S., Zimmermann, A., Fry, P., Gurung, G.S., Schneider, F., Speranza, C.I., Kiteme, B., Boillat, S., Serrano, E. and Hadorn, G.H., 2010. Researchers' roles in knowledge co-production: experience from sustainability research in Kenya, Switzerland, Bolivia and Nepal. Science and Public Policy, 37(4), pp.267-281.

25. Richard, K.T.K., Onyango, N.O.C., Mbuvi, J.P. and Kironchi, G., 2012. Climate Change and Variability: Farmers' Perception, Experience and Adaptation Strategies in Makueni County, Kenya. Asian Journal of Agriculture and Rural Development, 2(3), p.411.

26. Riedlinger, D., 1999. Climate change and the Inuvialuit of Banks Island, NWT: using traditional environmental knowledge to complement western science. Arctic, 52(4), pp.430-432.

27. Roncoli, M.C., Ingram, K.T., Jost, C.C., Kirshen, P.H. and Yaka, P., 2002, November. Farmers' behavioral responses to seasonal rainfall forecasts in the Sahel-Sudan. In 17th Symposium of the international farming systems association.

28. Ruto, S.J., Ongwenyi, Z.N. and Mugo, J.K., 2010. Educational marginalisation in northern Kenya. Paper commissioned for the EFA Global Monitoring Report.

29. Sánchez-Carnero, N., Rodríguez-Pérez, D., Couñago, E., Le Barzik, F. and Freire, J., 2016. Species distribution models and local ecological knowledge in marine protected areas: The case of Os Miñarzos (Spain). Ocean \& Coastal Management, 124, pp.66-

30. Speranza, C.I., Kiteme, B. and Wiesmann, U., 2008. Droughts and famines: the underlying factors and the causal links among agro-pastoral households in semi-arid Makueni district, Kenya. Global Environmental Change, 18(1), pp.220-233. 
31. Stone, D., Auffhammer, M., Carey, M., Hansen, G., Huggel, C., Cramer, W., Lobell, D., Molau, U., Solow, A., Tibig, L. and Yohe, G., 2013. The challenge to detect and attribute effects of climate change on human and natural systems. Climatic Change, 121(2), pp.381-395.

32. Thorpe, N.L., 2000. Contributions of Inuit ecological knowledge to understanding the impacts of climate change on the Bathurst caribou herd in the Kitikmeot region, Nunavut. Simon Fraser University.

33. UNDP (2007) 'Human Development Report 2007/2008:Fighting Climate Change;Human Solidarity in a Divided World.', , (), pp. [Online]. Available at: http://hdr.undp.org/en/reports/global/hrdr 2007/2008 (Accessed: January 2013).

34. Van Asselt, H., Gupta, J. and Biermann, F., 2005. Advancing the climate agenda: exploiting material and institutional linkages to develop a menu of policy options. Review of European Community \& International Environmental Law, 14(3), pp.255-264

35. Ziervogel, G. and Downing, T.E., 2004. Stakeholder networks: improving seasonal climate forecasts. Climatic Change, 65(1-2), pp.73-101 